See discussions, stats, and author profiles for this publication at: https://www.researchgate.net/publication/259544221

\title{
Fast pole figure acquisition using area detectors at the DiffAbs beamline - Synchrotron SOLEIL. Erratum
}

Article in Journal of Applied Crystallography · December 2013

DOI: $10.1107 / 50021889813027453$

\section{CITATIONS}

15

10 authors, including:

(a) Cristian Mocuta SOLEIL synchrotron 149 PUBLICATIONS $\mathbf{1 , 1 3 0}$ CITATIONS

SEE PROFILE

J. Fouet

Aix-Marseille Université

6 PUBLICATIONS 33 CITATIONS

SEE PROFILE

\section{READS}

193

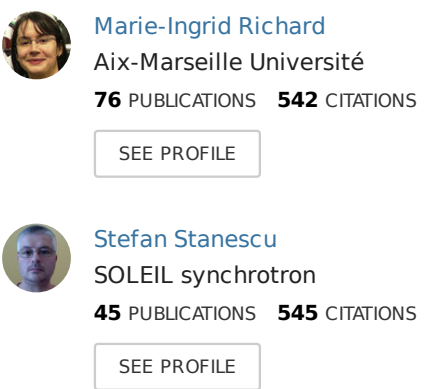

Some of the authors of this publication are also working on these related projects:

Interdisciplinary Multiscale Atomic Force Microscope Platform (IMAFMP) View project

Far from Equilibrium Phase Transitions View project 
Journal of

Applied

Crystallography

ISSN 0021-8898

\title{
Fast pole figure acquisition using area detectors at the DiffAbs beamline - Synchrotron SOLEIL
}

\author{
Cristian Mocuta, Marie-Ingrid Richard, Julie Fouet, Stefan Stanescu, \\ Antoine Barbier, Christophe Guichet, Olivier Thomas, Stéphanie \\ Hustache, Alexey V. Zozulya and Dominique Thiaudière
}

J. Appl. Cryst. (2013). 46, 1842-1853

Copyright (C) International Union of Crystallography

Author(s) of this paper may load this reprint on their own web site or institutional repository provided that this cover page is retained. Republication of this article or its storage in electronic databases other than as specified above is not permitted without prior permission in writing from the IUCr.

For further information see http://journals.iucr.org/services/authorrights.html

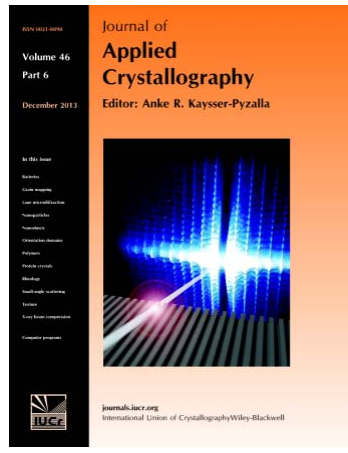

Journal of Applied Crystallography covers a wide range of crystallographic topics from the viewpoints of both techniques and theory. The journal presents papers on the application of crystallographic techniques and on the related apparatus and computer software. For many years, the Journal of Applied Crystallography has been the main vehicle for the publication of small-angle scattering papers and powder diffraction techniques. The journal is the primary place where crystallographic computer program information is published.

Crystallography Journals Online is available from journals.iucr.org 
Journal of

Applied

Crystallography

ISSN 0021-8898

Received 10 April 2013

Accepted 7 October 2013

(C) 2013 International Union of Crystallography

\section{Fast pole figure acquisition using area detectors at the DiffAbs beamline - Synchrotron SOLEIL}

\author{
Cristian Mocuta, ${ }^{\mathrm{a} *}$ Marie-Ingrid Richard, ${ }^{\mathrm{b}, \mathrm{c}}$ Julie Fouet, ${ }^{\mathrm{b}}$ Stefan Stanescu, ${ }^{\mathrm{a}}$ Antoine \\ Barbier, ${ }^{\mathrm{d}}$ Christophe Guichet, ${ }^{\mathrm{b}}$ Olivier Thomas, ${ }^{\mathrm{b}}$ Stéphanie Hustache, ${ }^{\mathrm{a}}$ Alexey V. \\ Zozulya $^{\mathrm{a}} \ddagger$ and Dominique Thiaudière ${ }^{\mathrm{a}}$
}

\begin{abstract}
a'Synchrotron SOLEIL, L'orme des Merisiers, Saint Aubin - BP 48, Gif-sur-Yvette, 91192, France, bIM2NP UMR 7334, Aix-Marseille Université, CNRS, Campus de St Jérôme, Marseille Cedex 20, 13397, France, 'ID-01 beamline, ESRF, 6 rue Jules Horowitz, Grenoble, 38043, France, and ${ }^{\mathbf{d} D S M}$ / IRAMIS/SPCSI, CEA-Saclay, Gif-sur-Yvette, 91191, France. Correspondence e-mail: mocuta@synchrotron-soleil.fr
\end{abstract}

\begin{abstract}
Structural anisotropy, for example texture, may govern important physical properties of thin film, such as electrical, magnetic and/or mechanical ones. Texture (orientation information) is typically observed and quantified by the measurement of so-called pole figures. An optimized experimental approach implemented at the DiffAbs beamline (Synchrotron SOLEIL) is presented here. Using an X-ray pixel area detector and synchrotron radiation sources, a complete pole figure (with resolutions adapted for metallic textured thin films, typically of the order of a few degrees) can be measured in time intervals as short as one minute. The necessary corrections enabling complete pole figure retrieval from the experimental data using this optimized approach are provided and discussed. A gain in measuring time by up to two orders of magnitude is found with respect to the use of a point detector (classical approach) under the same experimental conditions. Data measured using these two approaches are shown, compared and discussed.
\end{abstract}

\section{Introduction}

Many important physical properties of nanostructures are closely related to the internal microstructure, making knowledge of the microstructure of high importance. The crystalline structure of a sample and its degree of crystalline order are meaningful parameters. The texture of a crystalline sample can be described as the preferred orientation of its crystallites (Cullity, 1978) and can vary from simple (e.g. random, fibrelike; Pellegrino et al., 2012; Remiens et al., 2011; Fei et al., 2009; Beckers et al., 2010; Deniz \& Harper, 2008), to epitaxial (Remiens et al., 2011; Dong et al., 2001; Özcan et al., 2002; Barbier et al., 2007; Mocuta et al., 2003), to rather complex (e.g. axiotaxy; Detavernier et al., 2003; Detavernier \& Lavoie, 2004). As a consequence, it may be that the texture will affect or modify the properties of these materials, since a structural anisotropy is introduced.

Because of the need for a complete investigation of diffracted intensities over a full hemisphere, texture measurements are time consuming, which generally prevents investigation of the time evolution of crystal orientations in situ. Texture evolution is indeed an important issue in materials science. It is the result of several driving forces (surface and interface energy, elastic energy etc.) and an understanding of it is fundamental for controlling the final orientation, which

† Present address: DESY, Notkestrasse 85, Hamburg, 22607, Germany. ultimately controls the desired properties (mechanical, electrical etc.). Developing fast methods to record pole figures during phase transformations is thus very important and will allow us to increase our understanding of texture evolution in various materials.

The texture can be determined from a set of pole figures. We will concentrate here on using X-ray diffraction analysis for this purpose, but we should point out that other methods can be used to obtain such information [e.g. electron backscatter diffraction (EBSD) (see e.g. Zou \& Zhang, 2010, and references therein) or neutron diffraction (Wenk, 1991; Wenk et al., 2001)]. Let us describe briefly the pole figures that are obtained in some particular cases. Randomly oriented crystallites (powders) yield uniform intensity pole figures, while single-crystalline (or epitaxial) structures are shown by the presence of sharp peaks. Their symmetry and positions in the figure are related to the particular crystalline structure, its orientation in space, or a possible epitaxial relationship with respect to the substrate and the particular measured pole. More generally, the texture can be regarded as an intermediate state between the above ones. For a fibre texture (e.g. a particular crystalline direction is privileged, but other directions are randomly oriented), the result on the pole figure is the presence of a uniform intensity ring, at an elevation corresponding to the inclination of the fibre directions with respect to the sample normal and to the specific pole inves- 
tigated (Bulle-Lieuwma et al., 1992; Labat et al., 2000; Gaudet et al., 2011).

Following the approaches described by $\mathrm{He}$ (2009) and Gaudet et al. (2013), we will demonstrate in this paper an optimized method for fast acquisition of pole figures for texture measurements using area detectors (Wenk et al., 2001, 2009; He, 2009; Rodriguez-Navarro, 2007; Garbe, 2009; Voltolini et al., 2011; Gaudet et al., 2013) at synchrotron facilities, with possible applications for in situ experiments. Whereas Gaudet et al. (2013) provided specific examples and made available an online package (XRD-Texture; http://code. google.com $/ \mathrm{p} / \mathrm{xrd}$-texture) for interpretation of pole figures, we focus here on the experimental aspects of the technique in order to optimize the time needed for data acquisition and exploitation, which is expected to open a number of perspectives in using this approach. Indeed, long acquisition times for a complete set of data exclude the possibility of addressing rapid changes in the texture of a sample (including the appearance of new crystalline phases) during in situ measurements (e.g. thermal annealing, mechanical deformation etc.). Interest in data collection methods in order to access rapid texture changes has resulted in the development of single-diffraction-image approaches with area detectors (Wenk \& Grigull, 2003; Ischia et al., 2005), continuously scanning ('sweeping') techniques (Bunge et al., 2003; Skrotzki et al., 2003, 2008) and adaptive step approaches (Schaeben et al., 2007). The use of area detectors for diffraction experiments goes well beyond texture measurements; the reader may also see similar approaches using grazing-incidence geometry, as described by Schlepütz et al. (2005). We point out several advantages of using area detectors. The necessary corrections are detailed. We will show an example of pole figures recorded in this way and compare them with figures acquired under the very same experimental conditions (setup, $\mathrm{X}$-ray energy etc.) using a 'standard approach' (i.e. point detector). The article focuses on the fast acquisition and treatment of data, allowing pole figures to be obtained. We will show that acquisition of complete pole figures and the exploitation of the corresponding data in time intervals as short as one minute is achieved. Thus in situ experiments can be foreseen.

A $\mathrm{Pd}_{2} \mathrm{Si}$ layer on an $\mathrm{Si}(001)$ substrate was chosen as a model sample. A more thorough texture analysis and the calculation of orientation distribution functions (ODFs) are beyond the scope of the present article; the reader is instead referred to the work of Bunge (1965), Roe (1965), Matthies et al. (1988), Bernier et al. (2006), Hielscher \& Schaeben (2008) and Goh et al. (2009). The physical properties of this material are detailed elsewhere (Fouet, 2012; Fouet et al., 2013).

\section{Experiments}

\subsection{Test sample description}

The test sample is a $50 \mathrm{~nm}$-thick Pd film prepared by sputter deposition onto an HF-cleaned $\mathrm{Si}(001)$ substrate. During deposition, the substrate was rotated in order to homogenize the metal layer thickness. The metallic layer was fully transformed into a silicide $\left(\mathrm{Pd}_{2} \mathrm{Si}\right)$ layer after annealing in air for $300 \mathrm{~s}$ at $603 \mathrm{~K}$. It is known from previous studies (BulleLieuwma et al., 1992; Detavernier et al., 2003; Detavernier \& Lavoie, 2004; Alberti et al., 2005; Gaudet et al., 2010, 2011, 2013) that metal silicides can have a rather complex texture. This translates into complex pole figures, which are used here to show that all the fine features are fully reproduced when using the area detector. The important gain in the acquisition time is also highlighted.

\subsection{Pole figure measurements}

In order to access texture via pole figure measurements, the sample is mounted on a six-circle diffractometer, allowing for the necessary angular movements (Fig. 1) of both the sample (azimuth $\varphi_{\mathrm{s}}$, elevation $\psi_{\mathrm{s}}$ and incidence $\omega$ ) and the detector (scattering angle $2 \theta_{\text {Bragg) }}$. The detector angle is defining a particular family of crystalline planes $\{h k l\}$ with interplane distances $\mathrm{d}_{h k l}$ via Bragg's law:

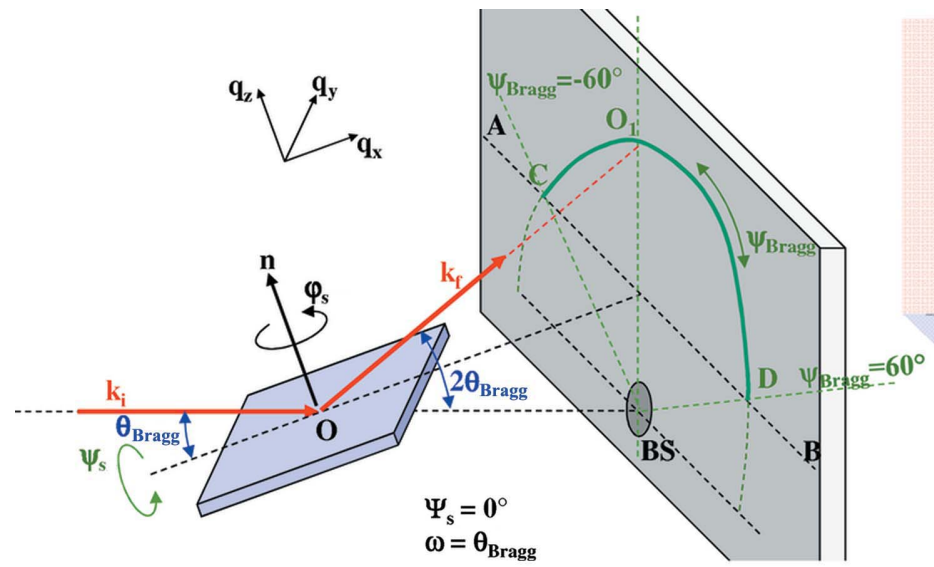

(a)

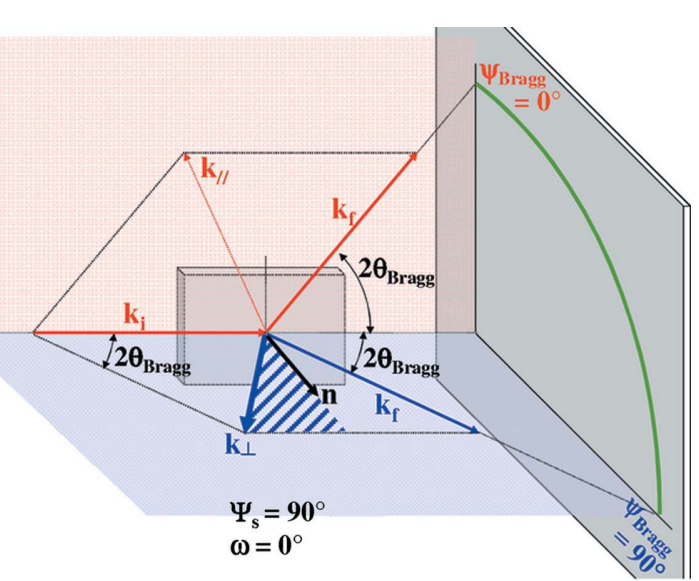

(b)

Figure 1

Schematics of the sample geometry and angular movements for the pole figure measurements. The detector angle, $2 \theta$, and sample rotation angles (the incident angle $\omega=\theta_{\mathrm{Bragg}}$, the sample azimuth $\varphi_{\mathrm{s}}$ and the sample elevation $\psi_{\mathrm{s}}$ ) are shown; BS denotes the X-ray beamstop (for the direct/transmitted beam) and $A B$ the sample horizon. The cases $\psi_{\mathrm{s}}=0^{\circ}$ and $\psi_{\mathrm{s}}=90^{\circ}$ are, respectively, shown in $(a)$ and $(b)$. 


$$
2 d_{h k l} \sin \theta_{\text {Bragg }}=n \lambda,
$$

$\theta_{\text {Bragg }}$ being the corresponding Bragg angle, $\lambda$ the X-ray wavelength and $n$ an integer. The sample surface normal is aligned (possibly using extra cradles) such as to coincide with the azimuthal rotation axis. The incident angle $\omega$ is set to $\theta_{\text {Bragg }}$ such as to have the normal to the sample surface coinciding with the scattering vector $\mathbf{k}=\mathbf{k}_{\mathrm{f}}-\mathbf{k}_{\mathrm{i}}$. Here $\mathbf{k}_{\mathrm{i}}$ and $\mathbf{k}_{\mathrm{f}}$ are the incident and scattered wavevectors, with their directions fixed by the X-ray incident beam and the direction of the detector position, respectively. Thus, for $\psi_{\mathrm{s}}=0^{\circ}$, the $(h k l)$ planes probed (detected) are the ones oriented parallel to the surface of the sample (Fig. 1a). The corresponding probed planes become perpendicular to the surface of the sample for $\psi_{\mathrm{s}} \simeq$ $90^{\circ}$ (Fig. 1b).

In the 'standard approach', a pole figure is measured using a point detector and a step-by-step acquisition of the data: the intensity of the chosen Bragg reflection is recorded while the sample is both rotated (azimuth $\varphi_{\mathrm{s}}$ ) and tilted (elevation $\psi_{\mathrm{s}}$ ) in the $0-180^{\circ}$ and $0-90^{\circ}$ ranges, respectively. This approach has the result of bringing into diffraction condition the differently oriented crystallites; high intensity is detected when the normal to these planes is along the scattering vector $\mathbf{k}$. The presence of such crystallites will then be represented by their position (azimuth and elevation) on a hemisphere in a pole figure. The intensity of the signal in the detector (and thus in the pole map) will be proportional to the volume of the sample (crystallites) exhibiting, for the $(h k l)$ pole, this particular orientation. The measured intensity at each point $\left(\varphi_{\mathrm{s}}, \psi_{\mathrm{s}}\right)$ is then reported on the pole figure.

In order to speed up the measurement, a linear detector may be used. An alternative way of measuring the pole figures is to map the scattered intensity using a two-dimensional detector (He, 2009; Voltolini et al., 2011; Wenk et al., 2001,
2009; Gaudet et al., 2011, 2013). We will show in the following the advantages of this approach: (i) an important gain in measuring time of the complete pole figure (more than one decade) and (ii) the possibility of acquiring simultaneously several partial pole figures in addition to the complete one.

The setup with an area detector is depicted schematically in Fig. 1. The area detector has a beamstop (BS) placed so as to absorb the direct/transmitted X-ray beam. The beam scattered by the $(h k l)$ planes will yield intensity which is recorded on the area detector at the intersection of the detector plane and the diffraction ring. In the following, we will denote by $\psi_{\text {Bragg }}$ the azimuthal coordinate of each point of the diffraction ring (same value of $2 \theta$ ) on the area detector, as shown schematically in the figure. For $\psi_{\mathrm{s}}=0^{\circ}$ (Fig. $1 a$ ), the $A B$ line represents the sample horizon: all the scattered intensity located below this line is fully attenuated by the sample itself. From geometrical considerations (sample horizon is close to half of the $2 \theta_{\mathrm{Bragg}}$ angle, i.e. is located at the half-distance between BS and the apex of the scattered signal, point $O_{1}$ ), the maximum available $\psi_{\text {Bragg }}$ range for the pole figure is $\Delta \psi_{\text {Bragg }} \simeq \Delta \psi_{\text {pole }}=$ $\pm 60^{\circ}$ (corresponding to the positions of points $C$ and $D$, respectively, on the area detector image). Fig. 1(b) depicts the situation $\psi_{\mathrm{s}} \simeq 90^{\circ}$ and $\omega=0^{\circ}$ : the sample surface (vertical plane in the figure) is almost parallel to the incident X-ray beam $\mathbf{k}_{\mathrm{i}}$. When the signal is extracted and geometry corrected from the diffraction ring $\left(\Delta \psi_{\text {Bragg }}=0-90^{\circ}\right.$ range $)$, an inaccessible region of the pole figure (corresponding to a range of the elevation angle $\psi_{\text {pole }}$ on the pole figure from 0 to $\theta_{\text {Bragg }}$ ) will be found. This is shown by the hatched angular range between the normal to the sample surface $\mathbf{n}$ and $\mathbf{k}_{\perp}$. By combining two such measurements $\left(\psi_{\mathrm{s}}=0^{\circ}\right.$ and $\left.\psi_{\mathrm{s}} \simeq 90^{\circ}\right)$, a complete pole figure can be generated, without any missing data for $\psi_{\text {pole }}=0-90^{\circ}$. We will note here that the angular ranges shown before can be extended if the size of the area

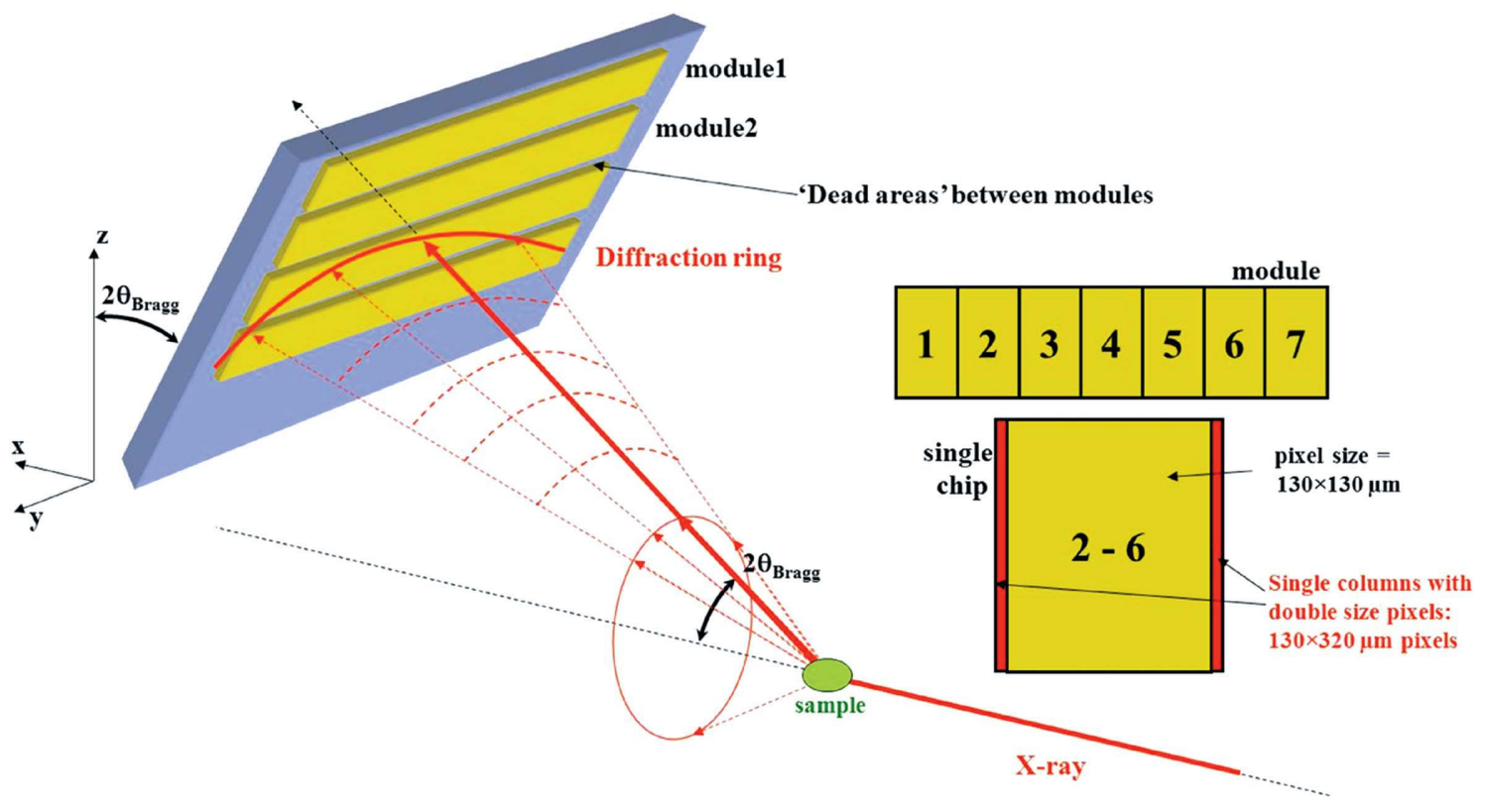

Figure 2

Schematic of the geometry of the XPAD (flat modules). The detector is carried by a motorized arm with two rotation angles ( $\delta$ and $\gamma$, in the vertical and horizontal planes, respectively) used to adjust its angular position. 
detector is large enough, high-energy X-rays are used, and the transmitted intensity is recorded and exploited as well. Consequently, the number of acquisitions for a complete pole figure could be reduced (see Appendix B).

\subsection{Characteristics of the $\mathrm{X}$-ray pixel area detector}

The development of large area X-ray detectors with high sensitivity, large dynamic range, low noise and fast response makes possible this kind of measurement at synchrotron facilities (Brönnimann et al., 2003; Ponchut et al., 2005, 2007; Ejdrup et al., 2009; Henrich et al., 2009; Basolo et al., 2007; Rossi et al., 1999; Delpierre et al., 2007). The X-ray pixel area detector (XPAD) (Delpierre et al., 2007; Medjoubi et al., 2010, 2012; Fertey et al., 2013, and references therein) used for this study has a $500 \mu \mathrm{m}$-thick Si sensor and is composed of eight modules (each of them of size $15.6 \times 72.8 \mathrm{~mm}$, pixelated silicon sensor); it is shown schematically in Fig. 2. Each module contains seven chips. The size of the pixels is $130 \times$ $130 \mu \mathrm{m}$ (in fact, the size is $100 \times 100 \mu \mathrm{m}$ with a $130 \mu \mathrm{m}$ pitch in both directions), except the last column of chip 1, the first column of chip 8 , and the first and last columns of the chips labelled 2-6, which have an approximately 2.5 times larger size in the horizontal direction. The modules can be mounted on a flat surface (Fig. 2) or tiled (Medjoubi et al., 2010) with respect to the average surface of the detector. If in the first case a significant dead area between modules (about $3.5 \mathrm{~mm}$ or 25 pixels) is found, the second geometry (slight overlap of the modules) will minimize this value to about 3 or 4 pixels, but with an increased complexity in the geometrical corrections needed to obtain accurate diffraction data (Hülsen et al., 2005; Le Bourlot et al., 2012; Fertey et al., 2013). A global threshold (known as ITH and scanned with a corresponding step in X-ray energy of $0.7 \mathrm{keV}$ ) is used for energy discrimination. Different pixels of the detector will have different characteristics; thus the effective threshold value will vary from pixel to pixel. A local threshold correction (DACL) is also performed to reduce the interpixel threshold dispersion. In order to prevent double counting of photons by nearby pixels, the threshold adjustment procedure should be performed with monoenergetic photons of an energy which is half of that used for measurements. In this case, a slightly higher energy (the fluorescence line of $\mathrm{Ge}, E \simeq 9.9 \mathrm{keV}$ for measurements performed at $18 \mathrm{keV}$ ) was used, ensuring the absence of

Figure 3 double photon counting. For more details, the reader is referred to Medjoubi et al. (2012). A distortion correction was not necessary for this system but could be performed by using an absorbing mask with small holes placed on a regular square grid (Paciorek et al., 1999a).

\section{Results}

The results shown hereafter were obtained mostly with a flat surface area detector and using an X-ray beam of energy $18 \mathrm{keV}[\lambda=0.688(8) \AA]$. The data set acquired with a point detector is mainly used for comparison purposes; in this case the X-ray beam energy was $8.048 \mathrm{keV}[\lambda=1.540$ (5) $\AA$ ] . The first step in analysing the data (XPAD images) consists of a field correction (of the possible non-uniform response of the various pixels of the detector). Then the correction of the particular geometry of the modules [flat (Le Bourlot et al., 2012) or tiled (Fertey et al., 2013)] and chips of the XPAD is done, resulting in a conversion of the measured data from the detector coordinates (pixel index) to diffraction angles and thus to reciprocal space [see also XRDUA (De Nolf \& Janssens, 2010; http://xrdua.ua.ac.be), FIT2D (Boesecke, 2007;
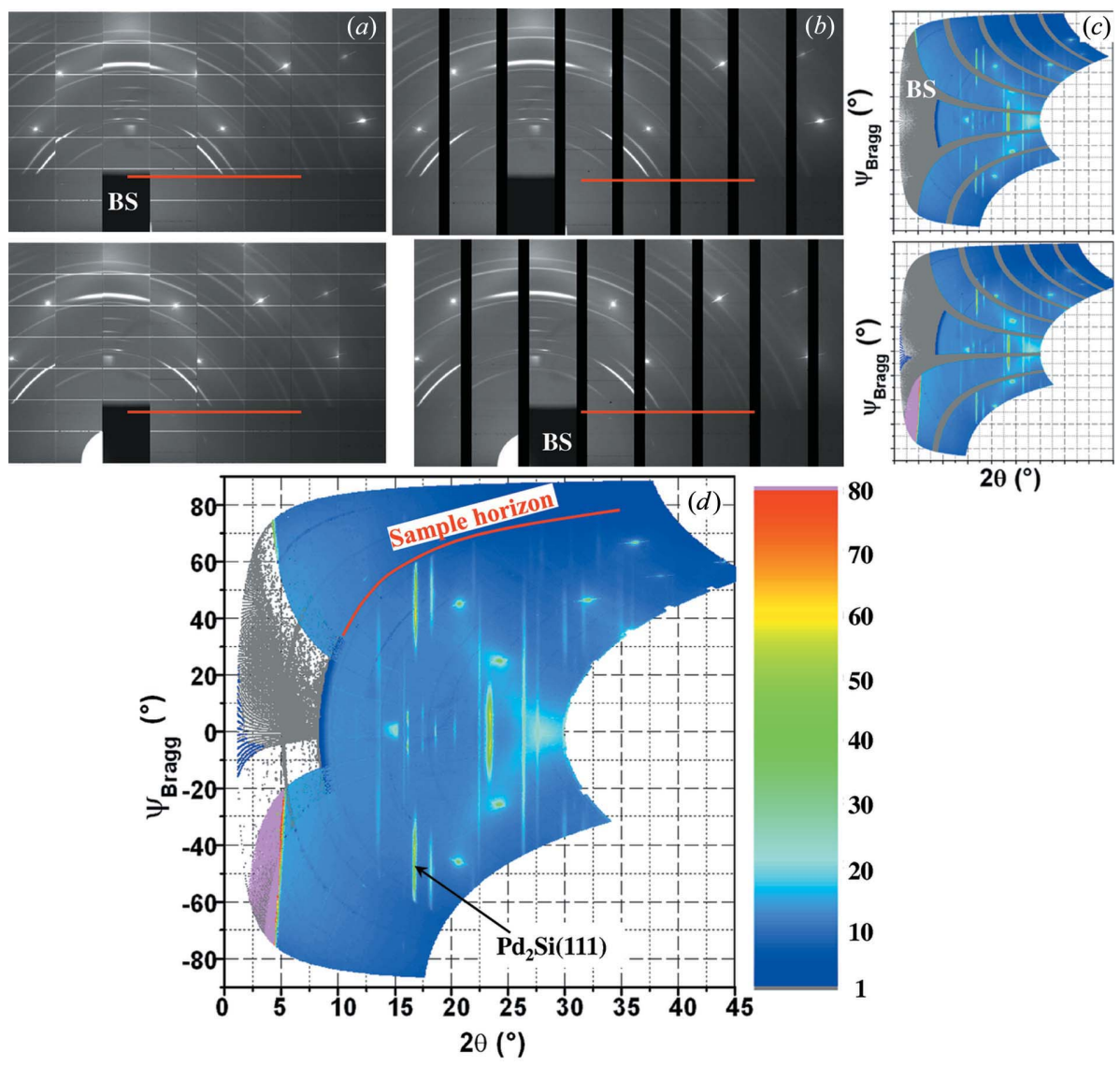

Illustration of the geometry correction of the XPAD. (a) Raw (as-acquired) images $\left(\omega=8.4^{\circ}, \delta=\right.$ $\left.11.8^{\circ}\right)$ measured for two lateral positions of the detector $\left(\gamma=0\right.$ and $3^{\circ}$, respectively), in order to be able to recover the missing data in the dead areas. The sample horizon is highlighted by the red line. Note the presence of the eight modules (vertical) with seven chips each. The double pixels between chips are visible as horizontal more intense lines. $(b)$ Images after the corrections (expand larger pixels and insert corresponding dead area pixels). (c) Generated $2 \theta-\psi_{\text {Bragg }}$ coordinates are combined into a single image $(d)$. Typical SNR in the images is of about 2-5 (see colour scale). 
http://www.esrf.eu/computing/scientific/FIT2D), XRD-Texture (Gaudet et al., 2013; http://code.google.com/p/xrd-texture) and xrayutilities (Kriegner et al., 2013; http://xrayutilities. sourceforge.net)]. The approach for this conversion is based on that reported by He (2009). A modified version is detailed in Appendix $A$. The result of the correction and conversion of the XPAD images into angular coordinates related to the diffraction geometry $\left(2 \theta_{\text {Bragg }}, \psi_{\text {Bragg }}\right)$ is shown in Fig. 3 . With the setup and the particular sample-to-detector distance used $(145 \mathrm{~mm})$, the detector resolution ( $2 \theta$ angular spread of a pixel) was found to be $0.051^{\circ}$.

To create pole figures $\left(\varphi_{\text {pole }}, \psi_{\text {pole }}\right)$, the signals originating from the different diffraction rings have to be integrated over defined angular ranges in the $2 \theta_{\text {Bragg }}$ and $\psi_{\text {Bragg }}$ directions (typically 0.25 and $1^{\circ}$, respectively, for this particular example). These values can be set as low as the abovementioned angular resolution of the detector if fine features are to be detailed. For this case, the rather 'high' intensity found in the Bragg peaks [a typical signal-to-noise ratio (SNR) of 3-5 is measured, depending on the considered Bragg peak] allows for a simple numerical integration of the peak intensity, even without any background subtraction. This is also the case when performing pole figure measurements with a point detector, the detector being placed at a fixed $2 \theta$ position. However, the available data set with an area detector allows the extraction of $2 \theta$ profiles at each measured point. The $2 \theta$ range should be wide enough to access the tails of the peak and perform a proper fitting procedure in order to remove the background (fluorescence, air scattering, diffuse signal etc.) and obtain data expected to be cleaner than in the case of using a point detector. Appendix $B$ explains how to calculate the polar azimuth $\varphi_{\text {pole }}$ and elevation $\psi_{\text {pole }}$ of a pole figure from knowledge of the scattering angle $\left(2 \theta_{\text {Bragg }}\right)$ on the diffraction ring and the azimuth $\psi_{\text {Bragg }}$ along the diffraction ring, and for each sample orientation $\left(\omega, \varphi_{\mathrm{s}}, \psi_{\mathrm{s}}\right)$. Appendix $B$ also describes how to choose the best angular orientations of the sample $\left(\omega, \varphi_{\mathrm{s}}, \psi_{\mathrm{s}}\right)$ such that, depending on the available $\psi_{\text {Bragg }}$ range on the detector, pole figures with maximum information and minimum data sets can be obtained.

We will also point out here that during the change in sample elevation for a complete pole figure measurement (from $\psi_{\mathrm{s}}=$ $0^{\circ}$ up to $\psi_{\mathrm{s}}=90^{\circ}$ ) the footprint of the X-ray beam on the sample is changing, and the probed sample volume (beam footprint on the sample) has to be taken into account and corrected for (Vlieg, 1997, 2000; Smilgies, 2002). Also, the synchrotron X-ray beam is linearly polarized in the horizontal plane. Thus, for all detector points characterized by $\psi_{\text {Bragg }} \neq$ $0^{\circ}$, a polarization correction on the measured intensity has to be applied (Appendix $B$ ).

Fig. 4 displays a part of a reconstructed pole figure $\left(\psi_{\text {pole }}<\right.$ $60^{\circ}$ and $\Delta \varphi=120^{\circ}$ ). Measuring a reduced azimuthal range is enough if the symmetry of the expected crystalline structure is known. The range measured here allows reconstruction of both fourfold and threefold symmetry signals. With the geometry depicted in Fig. 1 and the details in Appendix $A$ one can notice that a sector of the diffraction ring from a single detector image corresponds to a line (curve) on the pole map, covering an extended $\psi_{\text {pole }}$ range. Note as well a 'bending' of these data on the pole figure representation: it is not simply a straight line in the radial direction (i.e. $\varphi=$ constant), but there
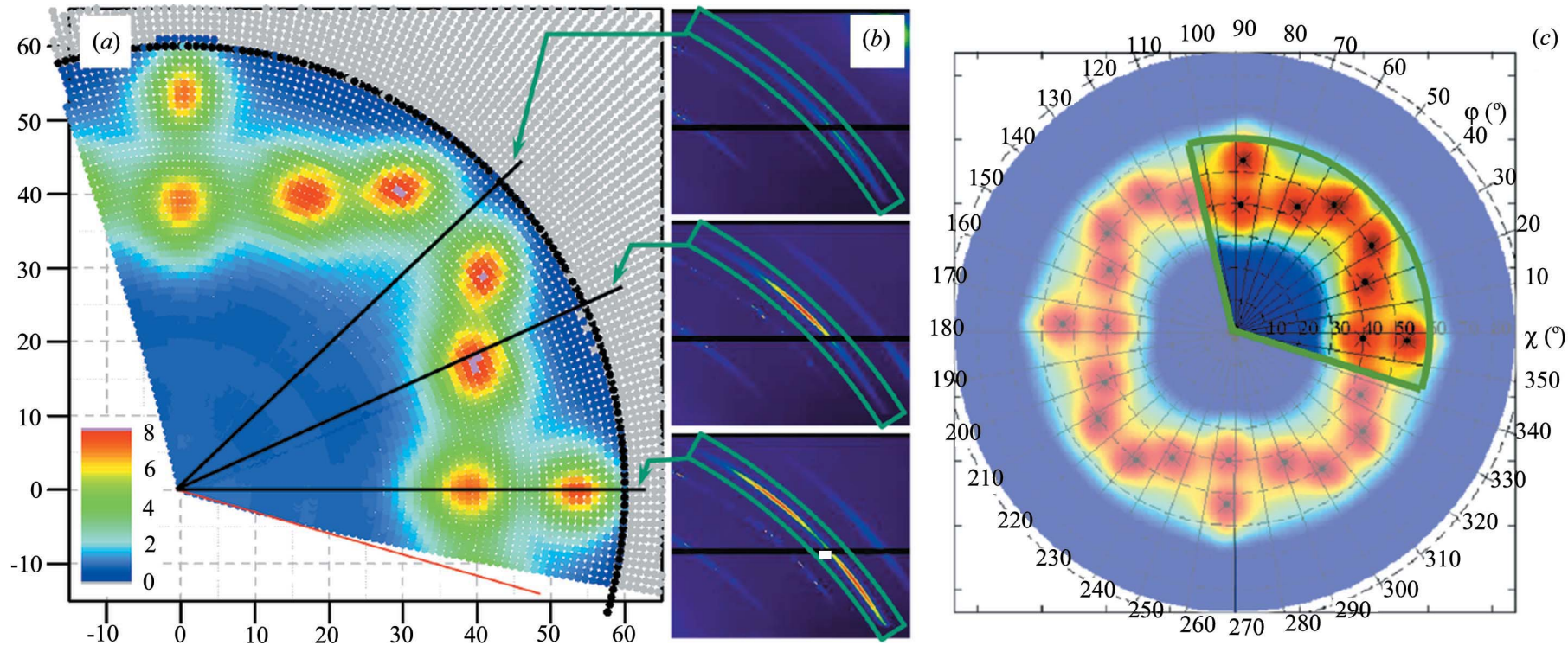

Figure 4

(a) The reconstructed pole figure using XPAD images. The pole $\mathrm{Pd}_{2} \mathrm{Si}(111)$ is shown $\left(2 \theta_{\mathrm{Bragg}}=16.8^{\circ}, \omega=8.4^{\circ}\right.$ at a beam energy of $\left.18 \mathrm{keV}\right)$. The black symbols (dots) represent the $\psi_{\text {pole }}=60^{\circ}$ data. Outside this region (i.e. $\psi_{\text {pole }}>60^{\circ}$, corresponding to the inaccessible transmitted geometry in this particular setup), the intensity values are close to the noise level (shown in grey colour). The red line renders more visible the effect of the azimuth correction (see text). The black lines show approximately the corresponding data on the area detector for azimuth values $\varphi_{\mathrm{s}}$ of 0,24 and $45^{\circ}$. The corresponding area detector images are shown in $(b)$. Note the different distributions of intensity on this ring and the position of the maximum of the intensity. (c) Pole figure obtained under the same experimental conditions by using a point detector and the 'classical' approach of scanning the azimuth $\varphi_{\mathrm{s}}$ and elevation $\psi_{\mathrm{s}}$. The data shown here were acquired for a range $\varphi_{\mathrm{s}}=0-180^{\circ}$ and symmetrized. For comparison, the same $\left(\psi_{\mathrm{s}}, \varphi_{\mathrm{s}}\right)$ range as in panel $(a)$ is highlighted; the rest of the figure is shaded. 
Table 1

Comparison of the acquisition time and other characteristic values for the same pole figures using the point detector and the area detector.

The example of the $\mathrm{Pd}_{2} \mathrm{Si}(111)$ pole measurement is detailed.

\begin{tabular}{|c|c|c|}
\hline & Point detector (point by point acquisition) & Area detector (XPAD) $\dagger$ \\
\hline Number of data acquisitions & $\psi_{\mathrm{s}} \times \varphi_{\mathrm{s}}: 91 \times 181=16471$ & $4 \varphi_{\mathrm{s}}: 4 \times 181=724$ \\
\hline Total exposure time & $0.1 \mathrm{~s}$ per point $=27 \min 30 \mathrm{~s}$ & $0.03 \mathrm{~s}$ per point $\simeq 22 \mathrm{~s}$ \\
\hline Dead time & $\sim$ Few minutes (e.g. readout time $\sim 10 \mathrm{~ms}$ per point) & $\psi_{\mathrm{s}}$ movements: $\sim$ few seconds \\
\hline Readout time & - & $\sim 0.01$ s per point: few seconds \\
\hline Total measurement time & $30 \mathrm{~min}$ & Given by the speed limit $\left(8^{\circ} \mathrm{s}^{-1}\right)$ of $\varphi_{\mathrm{s}}: 1 \mathrm{~min}$ \\
\hline
\end{tabular}

$\dagger$ Two sets of images $\left(\psi_{\mathrm{s}} \simeq 0^{\circ}\right.$ and $\left.\psi_{\mathrm{s}} \simeq 90^{\circ}\right)$ acquired at two detector positions $(\gamma)$ to recover the missing areas between modules

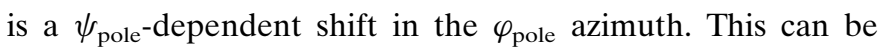
understood in terms of projection of the scattering vector in the plane of the surface (see also Appendix $B$ ). The agreement with the data obtained using the standard approach and the point detector is very good (Fig. $4 c$ ).

\section{Discussion}

For most of the textured films, typically a step of a fraction of a degree to a few degrees in $\psi_{\mathrm{s}}$ and $\varphi_{\mathrm{s}}$ is enough, since this corresponds to the typical full width at half-maximum of the corresponding Bragg peaks. These values can be easily adapted to the particular sample used. Moreover, by changing the distance from the sample to the area detector, the $2 \theta$ angular resolution (angular opening of one pixel) can also be tuned accordingly. In the particular examples considered here, a step of $0.5-1^{\circ}$ (both in azimuth and elevation) was used to reconstruct the pole figures, sometimes together with some pre-knowledge of the system symmetry (thus reducing the azimuth scan range to 90 or $120^{\circ}$ ). These values are, of course, dependent on the crystalline quality of the sample, but typically for textured metallic layers, they are in the range of a few degrees (Labat et al., 2000; Gergaud et al., 2003). In a 'standard' measurement of a pole figure using a point detector, one will map the values of $\psi_{\mathrm{s}}$ and $\varphi_{\mathrm{s}}$ in the $0-90^{\circ}$ and $0-180^{\circ}$ ranges, respectively (with a $1^{\circ}$ step, for example). As a consequence, with the approach described above and using a point detector, a number of about $91 \times 181=16471$ points (separated by $1^{\circ}$ ) had to be collected. At a high-intensity $\mathrm{X}$-ray source such as a synchrotron, exposure times per point in the $100 \mathrm{~ms}$ range or below can be foreseen, even for samples with low scattering power or small volumes (e.g. low- $Z$ elements and/or thin films). Continuous mode acquisitions, in which the intensities are acquired while the motors are moving ['on the fly'; see for example Medjoubi et al. (2013), and references therein] and are thus averaged over a certain angular range, are compatible with fast readout detectors (a few milliseconds) and fast $\varphi_{\mathrm{s}}$ rotations (up to several tens of degrees per second). Even in these special cases, measurement of a complete set of data will take $\sim 20-30 \mathrm{~min}$ (see Table 1). Of course, if higher angular resolutions are required, the acquisition time for the data increases.

In the case of the XPAD, by combining at least two sets of measurements $\left(\psi_{\mathrm{s}}=0^{\circ}\right.$ and $\left.\psi_{\mathrm{s}} \simeq 90^{\circ}\right)$ a full pole figure can be reconstructed. Moreover, an important gain can be achieved by using very short exposure times for each image (down to $10 \mathrm{~ms}$ ). Even for such short exposure times, clean and good contrast pole figures can be obtained. A comparison of data recorded with an XPAD and a point detector is shown in Fig. 4.

By using the XPAD in a continuous acquisition mode, the sample azimuth $\varphi_{\mathrm{s}}$ is rotated at a speed of $8^{\circ} \mathrm{s}^{-1}$ and movielike images are acquired, with at least one image obtained every $0.1 \mathrm{~s}$ (see also Table 1 ). Then the angular range of the measurement $\left(\varphi_{\mathrm{s}}=0-180^{\circ}\right)$ is covered in $\sim 23 \mathrm{~s}$. The fourfold symmetry of the data being known from previous tests, only a $110^{\circ}$ azimuth range is recorded. With a photon flux (up to $10^{12}$ photons $^{-1}$ in the X-ray beam) high enough to allow exposures as short as $10 \mathrm{~ms}$ per image and limited thus only by the speed of the motor (and its acceleration and deceleration), this range is measured in about $15 \mathrm{~s}$. Moreover, the presence of gaps (dead areas) in the surface covered by the XPAD required the acquisition of two sets of images to be superimposed (Fig. 3). With the two elevation angles needed for a complete pole figure measurement, the total acquisition time is slightly greater than $1 \mathrm{~min}$. We also stress here that a single data set (four-image sequence) is sufficient to generate many partial pole figures (Fig. 5), with the missing area in the centre of the pole figure increasing with increasing distance of $2 \theta$ from the $2 \omega$ value.

With the same assumptions as for the point detector, data acquisition using the XPAD can be done in about $1 \mathrm{~min}$ (Table 1). Let us note that, with a $10 \mathrm{~ms}$ exposure time per image, the total exposure time during a full measurement will amount $\sim 10 \mathrm{~s}$ (or even half of this time, if symmetry is used to measure reduced azimuth ranges). It is then the angular rotation speed required $\left(\sim 100^{\circ} \mathrm{s}^{-1}\right)$ which might become the limiting factor. The results we show here combine exposures of $30-100 \mathrm{~ms}$ per image. In this case, the SNR was good enough not to require any background subtraction (see earlier in the text): the pole figures are generated by simple numerical integration of the signal in the Bragg peaks around their maxima in a certain $2 \theta$ range. Tests with a $10 \mathrm{~ms}$ exposure were performed as well, the duration of the full acquisition being then limited only by the motor speed $\left(8^{\circ} \mathrm{s}^{-1}\right.$ in this case $)$. The same results were obtained with slightly degraded counting statistics and increased noise. The symmetry and position of the features of the pole figures can still be identified. We will point out here that such a test was also done using a highly attenuated (by a factor of 200) X-ray beam and still yielded a measured SNR of about 1.2-1.5. In this case, a proper back- 

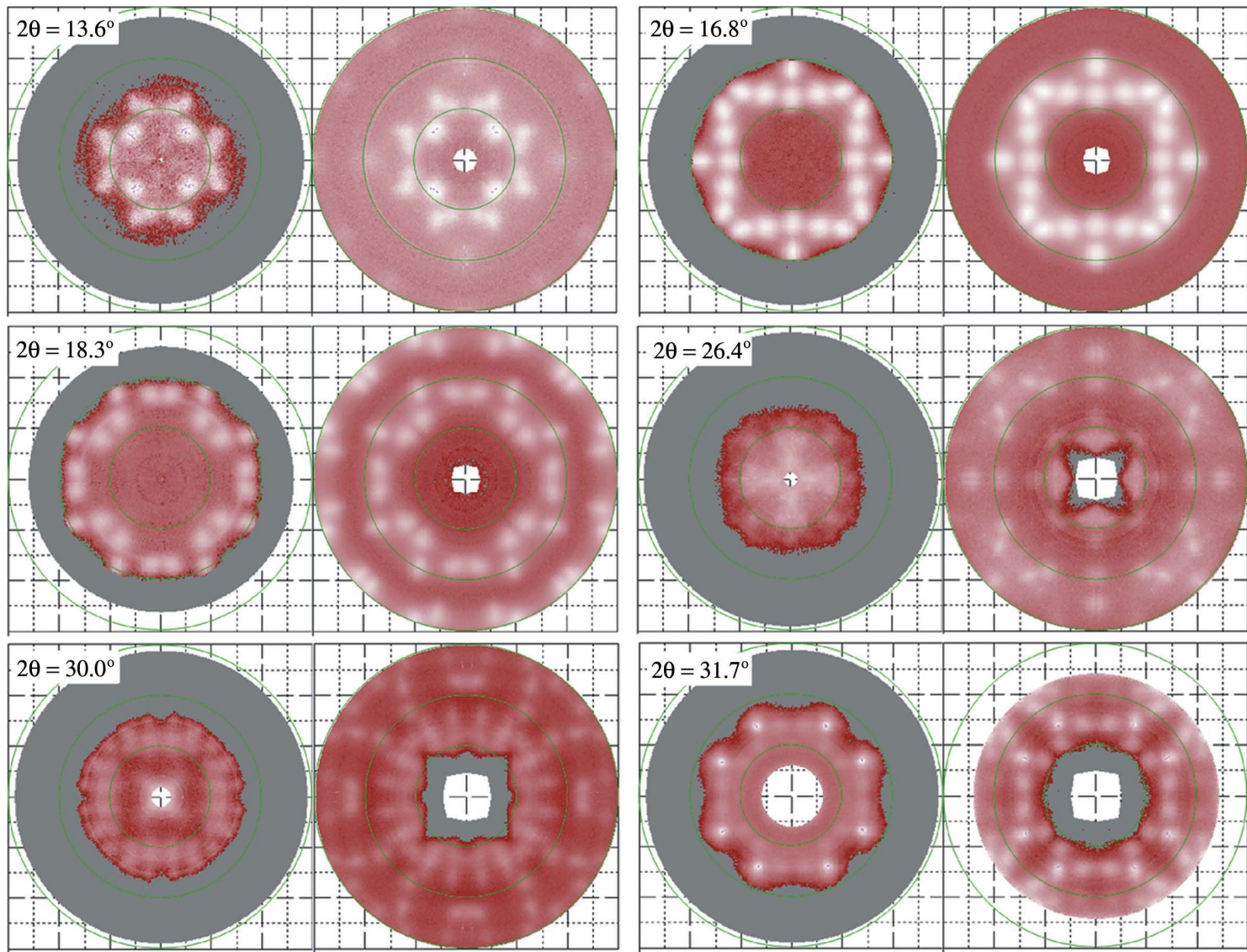

Figure 5

(a) Selected reconstructed pole figures [logarithmic colour scale; low (high) intensities are shown in red (white)] from a single data set ( $c f$. Table 1). The pole that was intended to be measured completely was $\operatorname{Pd}_{2} \operatorname{Si}(111)\left(2 \theta=16.8^{\circ}, \omega=8.4^{\circ}\right)$. The images reconstructed in the left and right columns correspond, respectively, to $\psi_{\mathrm{s}}=0$ and $89^{\circ}$, and full pole figures can be obtained by combining them. The $2 \theta$ value is noted for each panel. Note the inaccessible $\psi_{\text {pole }}$ range in the central region of the pole figure for $2 \theta \neq 16.8^{\circ}$. A $30^{\circ}$ step grid and concentric circles are traced.

ground subtraction procedure can improve the visibility of the data in the pole figures.

A computer code was developed to analyse and reconstruct the data. It was initially written in the macro language of ImageJ (http://rsbweb.nih.gov/ij/) (full open source, but slower) and later on using the Python (http://www.python.org) and $\mathrm{C}++$ (Stroustrup, 2009) programming languages. In this last case, generating a complete single pole figure from a set of data is done in about $30 \mathrm{~s}$, which is fully compatible with an online analysis of the data even in the case of fast acquisitions.

Measuring a single pole figure does not uniquely determine the orientation of texture components. Multiple poles, characteristic of various Bragg peaks $2 \theta_{\text {Bragg, }}$ are needed to calculate orientation distributions. We have shown above that measurement of a complete pole figure in reflection geometry requires at least two sets of images $\left(\right.$ e.g. $\psi_{\mathrm{s}}=0^{\circ}$ and $\left.\psi_{\mathrm{s}} \simeq 90^{\circ}\right)$. However, the figure recorded at $\psi_{\mathrm{s}} \simeq 90^{\circ}$ contains in fact several pole figures at the same time for the range $\psi_{\text {pole }}$ from $\delta / 2$ to $90^{\circ}$ (supposing that the area detector is large enough to record all the corresponding $\delta=2 \theta_{\text {Bragg }}$ range). Indeed, different $2 \theta_{\text {Bragg }}$ values are all recorded on the same image and only the central zone (delimited by the values $\psi_{\text {pole }}<\theta_{\text {Bragg }}$ ) is inaccessible. Thus, recording $N$ pole figures might require (for a proper choice of $2 \theta=\delta$ range and a large area detector) only $N+1$ images, reducing again the total acquisition time with respect to the case of using a point detector, where each pole figure has to be recorded independently.

When using an area detector, having access to extended $2 \theta$ profile information allows (after a fitting of the corresponding Bragg peak) not only the extraction of a background-corrected intensity (expected to render more visible the texture data in the pole figures) but also access to strain information.

It was not the aim of this report to discuss the results obtained using pole figures for the $\mathrm{Pd}_{2} \mathrm{Si}$ system, but rather to use it as a model compound in order to detail a fast acquisition approach using fast area detectors at synchrotron radiation sources. The obtained data allow the subsequent acquisition of stereographic projections, inverse pole figures or ODFs (Matthies et al., 1988, and references therein). Again, this goes beyond the scope of the present article.

\section{Conclusion}

We have shown that pole figure measurement using an area detector coupled to a proper geometrical correction and signal integration algorithm (e.g. accurate background subtraction) 
allows both fast and accurate acquisition of the diffraction signal (He, 2009; Gaudet et al., 2013) and increases the $\psi_{\text {Bragg }}$ range that can be measured in one shot. It has also been shown that measurements of several poles are possible within a single series of images. Of course, the area detector can always be used as a point detector (with the advantage mentioned above, of a proper signal integration and background subtraction), but any extension of the used $\psi_{\mathrm{s}}$ range (resulting in extension of the $\psi_{\text {Bragg }}$ range) represents a proportional gain with respect to the measurement using a point detector. It is also important to note that this approach allows pole figure measurements even with diffractometer geometries imposing limitations of angular movements (e.g. limited $\psi_{\mathrm{s}}$ range).

We validated this approach by several pole figure measurements performed on the same samples, and we compared these with similar measurements using the classical approach (point detector and $\varphi_{\mathrm{s}} / \psi_{\mathrm{s}}$ scans, same experimental conditions, same X-ray energy, same sample). A significant gain compared to the classical (point detector) method is obtained: up to two decades in the acquisition time of a complete pole figure and access from the same data set to a number of (partial) pole figures.

This approach clearly opens new experimental possibilities like in situ experiments (e.g. following in real time the formation of the texture during heating, catalytic reaction, magnetic/electric field exposition etc.). This approach also allows the continuous exploration of the $2 \theta$ values around the one of interest (i.e. continuously probing poles with increasing value of $\mathbf{k}$ ) in a three-dimensional mapping (Frazer et al., 2006; Gaudet et al., 2010, 2011 2013). With data acquired and exploited within several minutes, such a three-dimensional mapping can avoid problems of interception of Bragg peaks (for example $2 \theta$ positioning of a point detector) or crystalline phase changes in texture measurements performed during in situ phase transformations. Exploring a three-dimensional mapping also allows the retrieval of information like peak $2 \theta$ position, integrated intensity (area), and peak shape and width. Accurate quantification of the various phases and textures is possible, and strain pole figures can be measured (Le Bourlot, 2012; Faurie et al., 2009; Miller et al., 2005) while the sample is deformed (Djaziri et al., 2011). Such fast acquisitions and three-dimensional mapping also open the path to anomalous measurements, in which the beam energy is varied close to the absorption edge of an element, in order to enhance (or simply change) the contrast of the signal originating from particular atoms in the crystalline structure. A wide variety of textured systems (including highly textured ones, close to epitaxial layers) can be measured.

\section{APPENDIX $A$ \\ Geometrical correction of the images. Conversion from detector image to angular/diffraction coordinates}

The geometry of the experiment has to be very well known for a reliable conversion of the measured data from the detector coordinates (pixel index) to diffraction angles and thus to reciprocal space (Paciorek et al., 1999b). This approach is also discussed by He (2009) for the cases of flat (plane) and curved (cylindrical) detectors: a situation in which the detector is rotated around one axis (see Fig. 6, point denoted by $N$ ) was considered. We extend here this geometry for an XPAD (flat or tiled modules under a certain angle) that is carried by the detector arm of a six-circle diffractometer. The detector rotation can be done around two rotation axes (namely $\delta$ and $\gamma$ in Fig. 6, which are the in-plane and out-of-plane detector angles, respectively). We will also highlight some fine details to be considered when measuring pole figures for highly textured (ordered) systems.

Let us consider the point $M$ on the detector, which belongs to a diffraction ring (of scattering angle $2 \theta_{\text {Bragg }}$ ) originating from the sample. The diffraction angles $\left(2 \theta_{\text {Bragg }}, \psi_{\text {Bragg }}\right)$ from the laboratory coordinates $\left(x_{\mathrm{Lab}}, y_{\mathrm{Lab}}, z_{\mathrm{Lab}}\right)$, related to each pixel position $\left(x_{\mathrm{D}}, y_{\mathrm{D}}\right)$ on the plane detector in the general case depicted in Fig. 6, are obtained by considering the two corresponding rotation matrices of angles $\delta$ and $\gamma$, around the $z_{\text {Lab }}$ and $y_{\text {Lab }}$ axes, respectively (Fig. 6). They can be written as

$$
\begin{aligned}
2 \theta_{\text {Bragg }}= & \arccos \left[\left(x_{\mathrm{D}} \sin \delta-y_{\mathrm{D}} \cos \delta \sin \gamma+D_{0} \cos \delta\right)\right. \\
& \left./\left(D_{0}^{2}+x_{\mathrm{D}}^{2}+y_{\mathrm{D}}^{2}\right)^{1 / 2}\right]
\end{aligned}
$$

and

$$
\begin{aligned}
\psi_{\text {Bragg }}= & \arccos \left(\left(y_{\mathrm{D}} \cos \gamma+D_{0} \sin \gamma\right) /\left\{\left(D_{0} \sin \gamma+y_{\mathrm{D}} \cos \gamma\right)^{2}\right.\right. \\
& \left.\left.+\left[\sin \delta\left(D_{0} \cos \gamma-y_{\mathrm{D}} \sin \gamma\right)-x_{\mathrm{D}} \cos \delta\right]^{2}\right\}^{1 / 2}\right)
\end{aligned}
$$

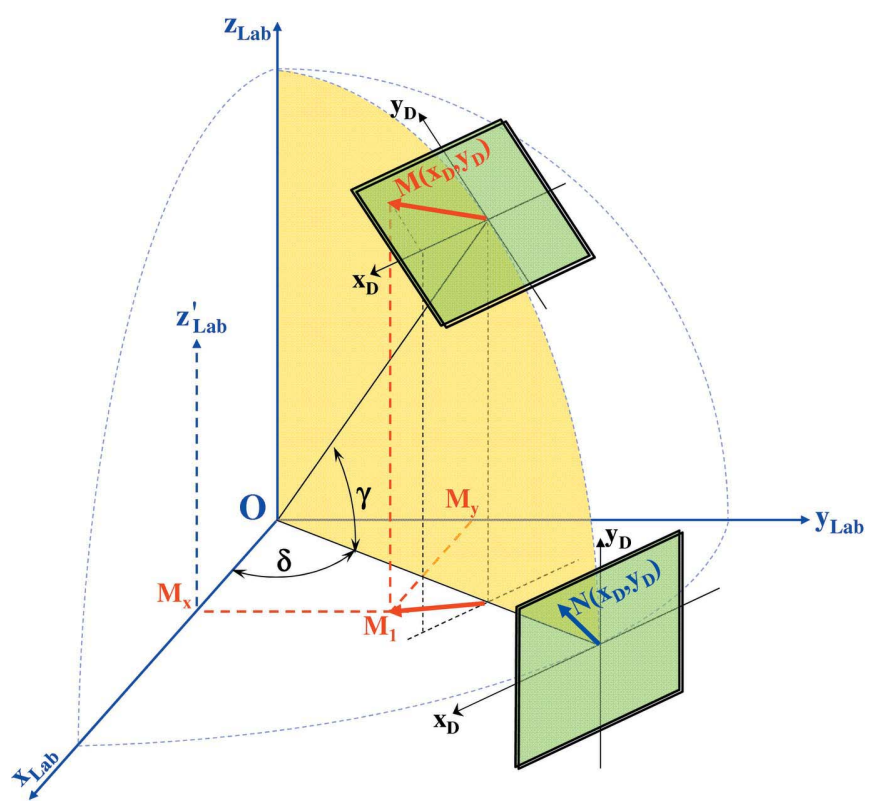

Figure 6

Positioning of the flat area detector. The X-ray incident beam is along the $O x_{\mathrm{Lab}}$ axis. The situation described by $\mathrm{He}$ (2009) corresponds to the particular case of $\gamma=0^{\circ}$. Angle $M_{x} O M=2 \theta_{\mathrm{Bragg}}$ is the Bragg diffraction angle and angle $z_{\mathrm{Lab}}^{\prime} M_{x} M$ is the azimuth angle of the diffraction ring ( $\theta_{\text {Bragg }}$ as illustrated in Fig. 1). 
with $D_{0}$ the sample-detector distance and the detector having its surface perpendicular to the incident X-ray beam (i.e. $\delta=$ $\gamma=0^{\circ}$, implying also an extra correction if tiled modules are used).

These formulae get simpler in the case of a plane (flat) detector which presents only one tilt angle. This situation is detailed by He (2009) and is a result of the above calculations [formulae (2) and (3)] for the particular case of $\gamma=0$ :

$$
2 \theta_{\text {Bragg }}=\arccos \left[\left(x_{\mathrm{D}} \sin \delta+D_{0} \cos \delta\right) /\left(D_{0}^{2}+x_{\mathrm{D}}^{2}+y_{\mathrm{D}}^{2}\right)^{1 / 2}\right]
$$

and

$$
\psi_{\text {Bragg }}=\arccos \left\{y_{\mathrm{D}} /\left[y_{\mathrm{D}}^{2}+\left(D_{0} \sin \delta-x_{\mathrm{D}} \cos \delta\right)^{2}\right]^{1 / 2}\right\} .
$$

\section{APPENDIX $B$ \\ Conversion to polar angles ( $\left.\psi_{\text {pole, }} \varphi_{\text {pole }}\right)$}

Starting from the known values of the scattering angle $\left(2 \theta_{\text {Bragg }}\right)$ on the diffraction ring, and the azimuth along this diffraction ring ( $\psi_{\text {Bragg }}$ ) calculated using formulae (2) and (3), it is possible to calculate, for each sample orientation (given by the set of angles $\omega, \psi, \varphi)$, the polar angles: the azimuth $\varphi_{\text {pole }}$ and the elevation $\psi_{\text {pole }}$.

With the geometry used, the scattering vector corresponding to any point on the diffraction ring (point characterized by the angles $2 \theta, \psi_{\text {Bragg }}$ ) will be (in the laboratory reference system)

$$
\mathbf{q}_{2 \theta}(\mathrm{Lab})=\left(\begin{array}{c}
-\sin \theta \\
-\cos \theta \sin \psi_{\text {Bragg }} \\
\cos \theta \cos \psi_{\text {Bragg }}
\end{array}\right)=\left(\begin{array}{c}
q_{x \mathrm{Lab}} \\
q_{y \mathrm{Lab}} \\
q_{z \mathrm{Lab}}
\end{array}\right) .
$$

In order to transform the coordinates of the scattering vector from the laboratory coordinate system to the sample coordinate system, the following rotations will be applied, namely a rotation $(\omega)$ around the $y$ axis, followed by a rotation $(-\psi)$ around the $x$ axis and a rotation $(\varphi)$ around the $z$ axis:

$$
\begin{aligned}
\mathbf{q}_{2 \theta}(\text { sample })= & \left(\begin{array}{l}
q_{x \text { Sample }} \\
q_{y \text { Sample }} \\
q_{z \text { Sample }}
\end{array}\right)=R_{z}(\varphi) R_{x}(-\psi) R_{y}(\omega) q_{2 \theta}(\mathrm{Lab}) \\
= & \left(\begin{array}{ccc}
\cos \varphi & -\sin \varphi & 0 \\
\sin \varphi & \cos \varphi & 0 \\
0 & 0 & 1
\end{array}\right)\left(\begin{array}{ccc}
1 & 0 & 0 \\
0 & \cos \psi & \sin \psi \\
0 & -\sin \psi & \cos \psi
\end{array}\right) \\
& \times\left(\begin{array}{ccc}
\cos \omega & 0 & \sin \omega \\
0 & 1 & 0 \\
-\sin \omega & 0 & \cos \omega
\end{array}\right)\left(\begin{array}{c}
-\sin \theta \\
-\cos \theta \sin \psi_{\text {Bragg }} \\
\cos \theta \cos \psi_{\text {Bragg }}
\end{array}\right) .
\end{aligned}
$$

The $x y z$ projections in the sample coordinate (reference) system are then

$$
\begin{aligned}
q_{x \text { Sample }}= & \cos \varphi\left(-\cos \omega \sin \theta+\sin \omega \cos \theta \cos \psi_{\text {Bragg }}\right) \\
& +\sin \varphi \cos \psi_{\text {sample }} \cos \theta \sin \psi_{\text {Bragg }} \\
& -\sin \varphi \sin \psi_{\text {sample }}\left(\sin \omega \sin \theta+\cos \omega \cos \theta \cos \psi_{\text {Bragg }}\right), \\
q_{y \text { Sample }}= & \sin \varphi\left(-\cos \omega \sin \theta+\sin \omega \cos \theta \cos \psi_{\text {Bragg }}\right) \\
& -\cos \varphi \cos \psi_{\text {sample }} \cos \theta \sin \psi_{\text {Bragg }} \\
& +\cos \varphi \sin \psi_{\text {sample }}\left(\sin \omega \sin \theta+\cos \omega \cos \theta \cos \psi_{\text {Bragg }}\right), \\
q_{z \text { Sample }} & =\sin \psi_{\text {sample }} \cos \theta \sin \psi_{\text {Bragg }} \\
& +\cos \psi_{\text {sample }}\left(\sin \omega \sin \theta+\cos \omega \cos \theta \cos \psi_{\text {Bragg }}\right) .
\end{aligned}
$$

The polar angles can now be easily calculated as

$$
\begin{aligned}
& \psi_{\text {pole }}=\arccos \left|q_{z \text { Sample }}\right|, \\
& \varphi_{\text {pole }}=\arccos \left[\left|q_{x \text { Sample }}\right| /\left(q_{x \text { Sample }}^{2}+q_{y \text { Sample }}^{2}\right)^{1 / 2}\right] .
\end{aligned}
$$

Note that in equation (9) the values of $\psi_{\text {pole }}$ are limited to positive ones $\left(0-90^{\circ}\right.$ range).

With a similar approach, the $x y z$ components of the scattering vector $\mathbf{k}_{\mathrm{f}}$ can be deduced, starting from the laboratory reference frame:

$$
\mathbf{k}_{\mathrm{f}}(\mathrm{Lab})=\left(\begin{array}{c}
\cos 2 \theta \\
-\sin 2 \theta \sin \psi_{\text {Bragg }} \\
\sin 2 \theta \cos \psi_{\text {Bragg }}
\end{array}\right)=\left(\begin{array}{c}
k_{\mathrm{f} x \mathrm{Lab}} \\
k_{\mathrm{f} y \mathrm{Lab}} \\
k_{\mathrm{f} z \mathrm{Lab}}
\end{array}\right) .
$$

Using similar relations to those above, $\mathbf{k}_{\mathrm{f}}$ can be converted into the sample coordinate system, and then the angle between the $z$ projection of the $\mathbf{k}_{\mathrm{f}}$ vector $\left(k_{\mathrm{f} z \text { Sample }}\right)$ and the sample normal (i.e. the $z$ axis of the sample coordinate system) can be calculated (similar to $\psi_{\text {pole }}$, but considering as well the sign of the $k_{\mathrm{f} z \text { Sample }}$ quantity). Any time that this angular value crosses the $90^{\circ}$ value (i.e. the change in sign of $k_{\mathrm{f} z \text { Sample }}$ from positive to negative) corresponds to the scattered beam entering into the sample (Laue diffraction). This criterion can be used to simulate the way the measurement of pole figures can be achieved with area detectors in reflection or transmission geometry.

In reflection geometry, at least two sets of images (two $\psi_{\mathrm{s}}$ values, e.g. 0 and $\sim 90^{\circ}$ ) are needed in order to record a complete pole figure (Figs. 7 and 8 ). For normal incidence $[\omega=$ $\delta / 2=\left(2 \theta_{\text {Bragg }}\right) / 2$ and $\psi=0^{\circ}$, only the $\Delta \psi_{\text {Bragg }}=0-60^{\circ}$ range is accessible in reflection geometry for the considered Bragg peak (Figs. $1 a, 4$ and 7). For $2 \theta$ angles that are different from the Bragg angle $\left(2 \theta \neq 2 \theta_{\text {Bragg }}=2 \omega\right)$, the accessible $\psi_{\text {Bragg }}$ range is different from the $0-60^{\circ}$ range, as can be seen in Figs. 3(c) and 8. Also, when $\psi_{\mathrm{s}} \simeq 90^{\circ}$ (sample surface is vertical and grazing incidence of the X-ray beam) the area with missing information in the pole figure is located close to zero elevation and spans up to precisely $\delta / 2$ (Figs. $1 b$ and 7). The accessible range in reflection geometry depends on the particular angular settings. The trajectory of the diffraction rings from the detector [points characterized by $\left(2 \theta, \psi_{\text {Bragg }}\right)$ values for $2 \theta=$ constant] is converted into points on the pole figures (azimuth $\varphi_{\text {pole }}$ and the elevation $\psi_{\text {pole }}$ ), as shown in Figs. 7 and 8. Formulae (8) and (9) were used, while also keeping track of whether a reflection (above sample surface) 


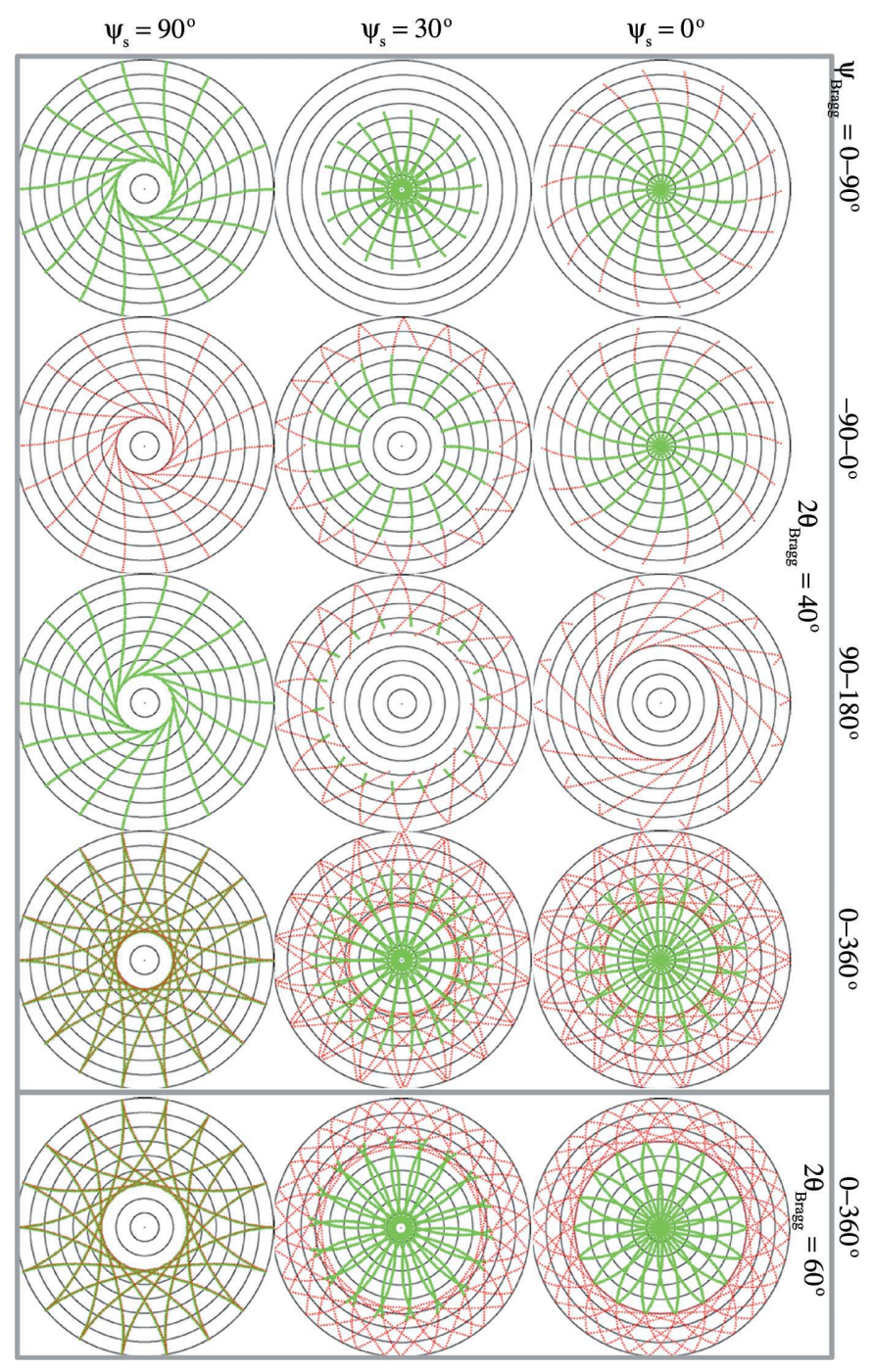

Figure 7

Pole figure simulations $\left(\omega=2 \theta_{\mathrm{Bragg}} / 2\right)$ : representation of the diffraction rings from an area detector $\left(2 \theta_{\mathrm{Bragg}}=\right.$ constant, $\psi_{\mathrm{Bragg}}=$ variable $)$ into polar coordinates. The sample azimuth $\left(\varphi_{\mathrm{s}}\right)$ is sampled in the $0-360^{\circ}$ range with a $20^{\circ}$ step; the diffraction ring from each image is converted into a curved line. The reflection and transmission geometries (supposing that the latter is accessible) are represented in green and red, respectively. The concentric dark circles have a step of $\Delta \psi_{\text {pole }}=10^{\circ}$. For $\psi_{\mathrm{s}}=0^{\circ}$, the accessible range is always $\Delta \psi_{\text {pole }}=0-60^{\circ}$, independent of the Bragg angle value. For $\psi_{\mathrm{s}}=90^{\circ}$, the inaccessible range close to the centre of the pole figure spans up to $\left(2 \theta_{\text {Bragg }}\right) / 2$.

or transmission (below sample surface) diffracted beam is detected: the red and green colours correspond, respectively, to the trajectories on polar maps of the signal recorded in reflection and transmission geometries. The rotation of the trajectories for $\psi_{\mathrm{s}}=90^{\circ}$ and various $\omega$ values explains why it is possible to reconstruct several partial pole figures from a set of measurements even if the condition $\omega=2 \theta_{\mathrm{Bragg}} / 2$ is not fulfilled. The requirement is to record a broad enough azimuthal range $\left(\varphi_{\mathrm{s}}\right)$ in order to be able to access the same range (e.g. $\left.\Delta \varphi_{\text {pole }}=0-90^{\circ}\right)$ in the pole figures for the various poles (various $2 \theta_{\mathrm{Bragg}}$ ).

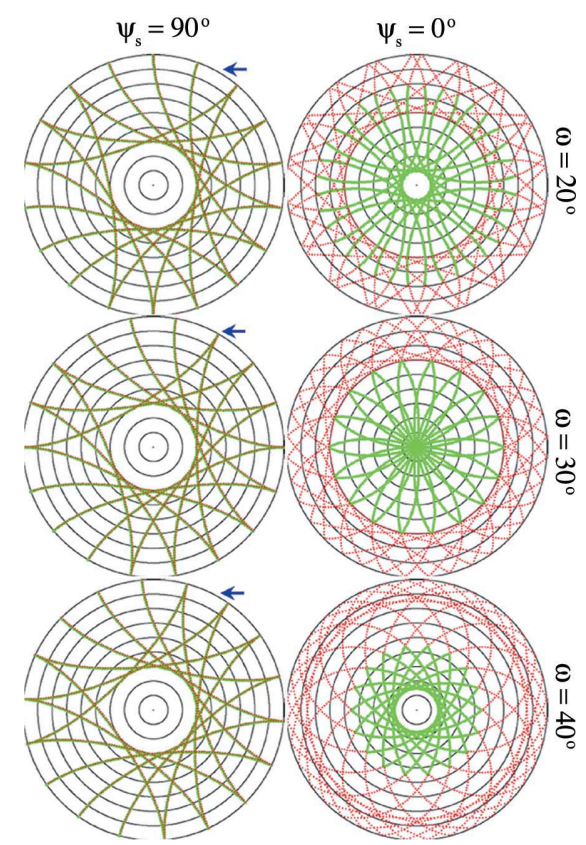

Figure 8

Pole figure simulations $\left(2 \theta_{\mathrm{Bragg}}=60^{\circ}\right)$ for various incident angles $\omega$. The same conventions as in Fig. 7 are used. Note the presence of missing data in the centre of the pole figures $\left(\psi_{\mathrm{s}}=0^{\circ}\right)$ in a range $\Delta \psi_{\text {pole }}=0^{\circ}$ to $\left|\left(2 \theta_{\text {Bragg }}\right) / 2-\omega\right|$. In the $\omega \neq 2 \theta_{\text {Bragg }} / 2$ configurations, using also data obtained at intermediate $\psi_{\mathrm{s}}$ positions $\left(0<\psi_{\mathrm{s}}<90^{\circ}\right)$ allows the missing data areas to be reduced (see supplementary material). For $\psi_{\mathrm{s}}=90^{\circ}$, the missing data range $0^{\circ}$ to $\left(2 \theta_{\mathrm{Bragg}}\right) / 2$ is always present. Note the rotation of the trajectories by an angle of $\left(2 \theta_{\mathrm{Bragg}}\right) / 2-\omega\left(\varphi_{\mathrm{s}}=0-270^{\circ}\right.$ range was considered to show this rotation and a reference position is indicated in all the maps by the blue arrow).

Movies showing the accessible range in measurements during $\psi_{\mathrm{s}}$ movement are also available ${ }^{\mathbf{1}}$ (same conventions as mentioned in Fig. 7). We will point out here that, even for configurations $\omega \neq\left(2 \theta_{\mathrm{Bragg}}\right) / 2$, it is possible to find a $\psi_{\mathrm{s}} \neq 0^{\circ}$ value which, combined with the data for $\psi_{\mathrm{s}}=90^{\circ}$, allows a complete reconstruction of the pole figure. This value is anyhow dependent on $\omega-\left(2 \theta_{\text {Bragg }}\right) / 2$. If the range in which the diffraction angle $2 \theta$ will span is known, it can be beneficial to use these trajectory simulations. They allow determination of the best angular orientation of the sample $\left(\omega, \psi_{\mathrm{s}}\right.$ values, $\varphi_{\mathrm{s}}$ azimuth ranges) such that, depending on the available $\psi_{\text {Bragg }}$ range on the detector, pole figures with maximum information can be obtained.

The example detailed here (continuously scanning the sample azimuth $\varphi_{\mathrm{s}}$ ) also shows that for particular cases in which the transmitted scattered X-ray beam can be recorded (i.e. thin sample and/or high-energy X-ray beam, red curves in Figs. 7 and 8) the number of acquisitions can be reduced even

\footnotetext{
${ }^{\mathbf{1}}$ The movies discussed in this paper are available from the IUCr electronic archives (Reference: RW5043). Services for accessing this material are described at the back of the journal. In these movies, the coordinates of diffraction rings recorded on the area detector after geometry corrections $\left(2 \theta_{\text {Bragg }}=\right.$ constant, $\psi_{\text {Bragg }}=$ variable $)$ are shown as $\left(\varphi_{\text {pole }}, \psi_{\text {pole }}\right)$ trajectories on pole figures. A $360^{\circ}$ range in $\varphi_{\mathrm{s}}$ and various $\psi_{\text {Bragg }}$ ranges are considered. A $\psi_{\mathrm{s}}$ scan with area detector is illustrated each time (for details, see also the corresponding legend included in the movie sequences).
} 
further. The choice of the measurement geometry can be different as well. Measuring two-dimensional polar maps (or probing the reciprocal space in three dimensions with an area detector) can be achieved also by rotating the sample around different directions (Bunge et al., 2003; He, 2009; Gaudet et al., 2013).

\section{B1. The polarization correction}

Considering the case of a polarization of $\mathbf{k}_{\mathbf{i}}$ along the $\mathbf{y}$ direction, it can be described by the vector

$$
\hat{\mathbf{p}}\left(\mathbf{k}_{\mathrm{i}}\right)=\left(\begin{array}{l}
0 \\
1 \\
0
\end{array}\right)
$$

Considering the outgoing/scattered beam $\left(\mathbf{k}_{\mathbf{f}}\right)$ given by equation (10), the polarization of the beam scattered by the sample can be written as

$$
\hat{\mathbf{p}}\left(\mathbf{k}_{\mathrm{f}}\right)=\left[1+\left(\tan 2 \theta \sin \psi_{\text {Bragg }}\right)^{2}\right]^{-1 / 2}\left(\begin{array}{c}
\tan 2 \theta \sin \psi_{\text {Bragg }} \\
1 \\
0
\end{array}\right) .
$$

Thus the measured intensity in each pixel of the XPAD will be

$$
\begin{aligned}
I_{\text {measure }}\left(2 \theta, \psi_{\text {Bragg }}\right)= & I_{\text {diffracted }}\left(2 \theta, \psi_{\text {Bragg }}\right) \\
& \times\left[1+\left(\tan 2 \theta \sin \psi_{\text {Bragg }}\right)^{2}\right]^{-1 / 2} .
\end{aligned}
$$

This formula leads to the well known polarization corrections of 1 and $1 / \cos \left(2 \theta_{\mathrm{Bragg}}\right)$, for the particular cases of $\psi_{\mathrm{Bragg}}=0^{\circ}$ (scattering in the vertical diffraction plane, $x O z$ ) and $\psi_{\mathrm{Bragg}}=$ $90^{\circ}$ (scattering in the horizontal diffraction plane, $x O y$ ), respectively.

\section{B2. The beam footprint correction}

The measurements described here were performed at several (two) elevation angles $\psi_{\mathrm{s}}$. As a consequence, the illumination function on the sample will change, since the incident angle is also changing. This change of the illuminated sample surface (i.e. sample volume probed by the X-rays) has to be taken into account as a correction factor when generating a full pole figure ( $\psi_{\text {pole }}$ in the $0-90^{\circ}$ range $)$. In the case of transmission (Laue) geometry, the beam absorption can be calculated as well and considered.

Moreover, when applying a grazing-like geometry ( $\psi_{\mathrm{s}}$ close to $0^{\circ}$ ) and depending on the sample and beam sizes, it can be that only part of the X-ray beam is intercepted and the beam footprint on the sample spans from one edge to the other. For a general sample shape, the area of the illuminated surface will change as well when the sample azimuth $\varphi_{\mathrm{s}}$ is rotated. This illuminated area can be calculated numerically if the beam size and beam profile are known (most of the time the latter is assimilated to a Gaussian), as well as the sample shape, its dimensions and the scattering geometry (angles). This correction will have to be calculated for each particular setup (see also Schlepütz et al., 2005; Vlieg, 1997).
Other corrections, taking into account the interception of the scattered beam by the detector, the absorption path of the photons in the Si sensor depending on the position of each pixel (incidence of the scattered beam on the XPAD) etc., can be foreseen but will not be discussed here.

\section{APPENDIX $C$}

\section{Synoptic/abbreviations/list of symbols}

(1) Diffractometer angles (see also Figs. 1 and 2):

$2 \theta=\delta=$ detector $2 \theta$ (X-ray scattering) angle, in the vertical scattering plane.

$\gamma=$ detector (X-ray scattering) angle, in the horizontal scattering plane.

$\omega=$ incidence angle. This is the angle between the X-rays and the sample surface, measured in the vertical scattering plane. The sample surface normal is in the vertical scattering plane.

$\varphi_{\mathrm{s}}=$ sample azimuth (rotation) and the corresponding diffractometer angle.

$\psi_{\mathrm{s}}=$ sample elevation and the corresponding diffractometer angle.

(2) Diffraction space related (see also Fig. 1):

$2 \theta_{\text {Bragg }}=2 \theta_{h k l}, \quad \theta_{\text {Bragg }}=$ Bragg diffraction angle corresponding to certain $(h k l)$ crystalline planes.

$\psi_{\text {Bragg }}=$ azimuthal angle on the diffraction ring, measured on the area detector with respect to the vertical scattering plane.

$\mathbf{k}_{\mathrm{i}}, \mathbf{k}_{\mathrm{f}}=$ incident and scattered vectors, respectively.

$\mathbf{k}=\Delta \mathbf{k}=\mathbf{k}_{\mathrm{f}}-\mathbf{k}_{\mathrm{i}}=$ momentum transfer.

$\lambda=$ wavelength of the X-rays used for the experiment.

(3) Pole figure angles (coordinates) (see also Figs. 1 and 2):

$\psi_{\text {pole }}=$ elevation angle on the pole figure.

$\varphi_{\text {pole }}=$ azimuthal angle on the pole figure.

The measurements reported here were performed on the DiffAbs beamline at Synchrotron SOLEIL (Sychrotron SOLEIL), Gif-Sur-Yvette, France, using the X-ray area pixel detector XPAD, developed in a collaboration by Synchrotron SOLEIL, CNRS CPPM (Marseille, France) and CNRS Institut Néel (Grenoble, France). We thank the DiffAbs beamline staff for excellent support during the experiment. Part of this project was financed by the ANR TAPAS (Tomographic Atom Probe for Advanced Silicide) under project No. ANR-08-027-01.

\section{References}

Alberti, A., Bongiorno, C., Cafra, B., Mannino, G., Rimini, E., Metzger, T., Mocuta, C., Kammler, T. \& Feudel, T. (2005). Acta Cryst. B61, 486-491.

Barbier, A., Bezencenet, O., Mocuta, C., Moussy, J. B., Magnan, H., Jedrecy, N., Guittet, M. J. \& Gautier-Soyer, M. (2007). Mater. Sci. Eng. B, 144, 19-22.

Basolo, S. et al. (2007). J. Synchrotron Rad. 14, 151-157. 
Beckers, M., Eriksson, F., Lauridsen, J., Baehtz, C., Jensen, J. \& Hultman, L. (2010). Phys. Status Solidi Rapid Res. Lett. 4, 121123.

Bernier, J. V., Miller, M. P. \& Boyce, D. E. (2006). J. Appl. Cryst. 39, 697-713.

Boesecke, P. (2007). J. Appl. Cryst. 40, s423-s427.

Brönnimann, C., Eikenberry, E., Horisberger, R., Hülsen, G., Schmitt, B., Schulze-Briese, C. \& Tomizaki, T. (2003). Nucl. Instrum. Methods Phys. Res. Sect. A, 510, 24-28.

Bulle-Lieuwma, C. W. T., van Ommen, A. H., Hornstra, J. \& Aussems, C. N. A. M. (1992). J. Appl. Phys. 71, 2211-2224.

Bunge, H. J. (1965). Z. Metall. 56, 872-874.

Bunge, H. J., Wcislak, L., Klein, H., Garbe, U. \& Schneider, J. R. (2003). J. Appl. Cryst. 36, 1240-1255.

Cullity, B. D. (1978). Elements of X-ray Diffraction, 2nd ed. Reading: Addison-Wesley.

Delpierre, P. et al. (2007). Nucl. Instrum. Methods Phys. Res. Sect. A, 572, 250-253.

Deniz, D. \& Harper, J. M. E. (2008). J. Appl. Phys. 104, 063519.

De Nolf, W. \& Janssens, K. (2010). Surf. Interface Anal. 42, 411-418.

Detavernier, C. \& Lavoie, C. (2004). Appl. Phys. Lett. 84, 3549-3551.

Detavernier, C., Ozcan, A. S., Jordan-Sweet, J., Stach, E. A., Tersoff, J., Ross, F. M. \& Lavoie, C. (2003). Nature, 426, 641-645.

Djaziri, S., Renault, P.-O., Hild, F., Le Bourhis, E., Goudeau, P., Thiaudière, D. \& Faurie, D. (2011). J. Appl. Cryst. 44, 1071-1079.

Dong, L., Srolovitz, D. J., Was, G. S., Zhao, Q. \& Rollett, A. D. (2001). J. Mater. Res. 16, 210-216.

Ejdrup, T., Lemke, H. T., Haldrup, K., Nielsen, T. N., Arms, D. A., Walko, D. A., Miceli, A., Landahl, E. C., Dufresne, E. M. \& Nielsen, M. M. (2009). J. Synchrotron Rad. 16, 387-390.

Faurie, D., Castelnau, O., Brenner, R., Renault, P.-O., Le Bourhis, E. \& Goudeau, Ph. (2009). J. Appl. Cryst. 42, 1073-1084.

Fei, W. D., Liu, C. Q., Ding, M. H., Li, W. L. \& Wang, L. D. (2009). Rev. Sci. Instrum. 80, 093903.

Fertey, P., Alle, P., Wenger, E., Dinkespiler, B., Cambon, O., Haines, J., Hustache, S., Medjoubi, K., Picca, F., Dawiec, A., Breugnon, P., Delpierre, P., Mazzoli, C. \& Lecomte, C. (2013). J. Appl. Cryst. 46, 1151-1161.

Fouet, J. (2012). PhD thesis, Université Aix-Marseille, France.

Fouet, J., Texier, M., Richard, M.-I., Connetable, D. \& Thomas, O. (2013). In preparation.

Frazer, C. S., Rodriguez, M. A. \& Tissot, R. G. (2006). Powder Diffr. 21, 102-104.

Garbe, U. (2009). J. Appl. Cryst. 42, 730-733.

Gaudet, S., Coia, C., Desjardins, P. \& Lavoie, C. (2011). J. Appl. Phys. 107, 093515.

Gaudet, S., De Keyser, K., Lambert-Milot, S., Jordan-Sweet, J., Detavernier, C., Lavoie, C. \& Desjardins, P. (2013). J. Vac. Sci. Technol. A, 31, 021505.

Gaudet, S., Desjardins, P. \& Lavoie, C. (2010). J. Appl. Phys. 110, 113524.

Gergaud, P., Megdiche, M. \& Thomas, O. (2003). Appl. Phys. Lett. 83, 1334-1336.

Goh, A., Lenglet, C., Thompson, P. M. \& Vidal, R. (2009). Medical Image Computing and Computer-Assisted Intervention - MICCAI 2009, Part 1, LNCS 5761, edited by G.-Z. Yang, D. J. Hawkes, D. Rueckert, A. Noble \& C. Taylor. Berlin, Heidelberg: SpringerVerlag.

He, B. B. (2009). Two Dimensional X-ray Diffraction. Hoboken: John Wiley and Sons.

Henrich, B., Bergamaschi, A., Broennimann, C., Dinapoli, R., Eikenberry, E., Johnson, I., Kobas, M., Kraft, P., Mozzanica, A. \& Schmitt, B. (2009). Nucl. Instrum. Methods Phys. Res. Sect. A, 607, 247-249.

Hielscher, R. \& Schaeben, H. (2008). J. Appl. Cryst. 41, 1024-1037.

Hülsen, G., Brönnimann, C. \& Eikenberry, E. (2005). Nucl. Instrum. Methods Phys. Res. Sect. A, 548, 540-554.
Ischia, G., Wenk, H.-R., Lutterotti, L. \& Berberich, F. (2005). J. Appl. Cryst. 38, 377-380.

Kriegner, D., Wintersberger, E. \& Stangl, J. (2013). J. Appl. Cryst. 46, $1162-1170$.

Labat, S., Gergaud, P., Thomas, O., Gilles, B. \& Marty, A. (2000). J. Appl. Phys. 87, 1172.

Le Bourlot, C. (2012). PhD thesis, Université Paris Nord, France.

Le Bourlot, C., Landois, P., Djaziri, S., Renault, P.-O., Le Bourhis, E., Goudeau, P., Pinault, M., Mayne-L'Hermite, M., Bacroix, B., Faurie, D., Castelnau, O., Launois, P. \& Rouzière, S. (2012). J. Appl. Cryst. 45, 38-47.

Matthies, S., Wenk, H.-R. \& Vinel, G. W. (1988). J. Appl. Cryst. 21, 285-304.

Medjoubi, K., Bucaille, T., Hustache, S., Bérar, J.-F., Boudet, N., Clemens, J.-C., Delpierre, P. \& Dinkespiler, B. (2010). J. Synchrotron Rad. 17, 486-495.

Medjoubi, K., Leclercq, N., Langlois, F., Buteau, A., Lé, S., Poirier, S., Mercère, P., Sforna, M. C., Kewish, C. M. \& Somogyi, A. (2013). J. Synchrotron Rad. 20, 293-299.

Medjoubi, K. et al. (2012). J. Synchrotron Rad. 19, 323-331.

Miller, M. P., Bernier, J. V., Park, J. \& Kazimirov, A. (2005). Rev. Sci. Instrum. 76, 113903.

Mocuta, C., Barbier, A., Lafaye, S., Bayle-Guillemaud, P. \& Panabière, M. (2003). Phys. Rev. B, 68, 014416.

Özcan, A. S., Ludwig, K. F., Rebbi, P., Lavoie, C., Cabral, C. \& Harper, J. M. E. (2002). J. Appl. Phys. 92, 5011-5018.

Paciorek, W. A., Meyer, M. \& Chapuis, G. (1999a). Acta Cryst. A55, 543-557.

Paciorek, W. A., Meyer, M. \& Chapuis, G. (1999b). J. Appl. Cryst. 32, 11-14.

Pellegrino, G., Bongiorno, C., Ravesi, S. \& Alberti, A. (2012). J. Phys. D Appl. Phys. 45, 355301.

Ponchut, C., Clément, J., Rigal, J., Papillon, E., Vallerga, J., LaMarra, D. \& Mikulec, B. (2007). Nucl. Instrum. Methods Phys. Res. Sect. A, 576, 109-112.

Ponchut, C., Zontone, F. \& Graafsma, H. (2005). IEEE Trans. Nucl. Sci. 52, 1760-1765.

Remiens, D., Yang, L., Ponchel, F., Legier, J. F., Chateigner, D., Wang, G. \& Dong, X. (2011). J. Appl. Phys. 109, 114101.

Rodriguez-Navarro, A. B. (2007). J. Appl. Cryst. 40, 631-634.

Roe, R. (1965). J. Appl. Phys. 36, 2024-2031.

Rossi, G., Renzi, M., Eikenberry, E. F., Tate, M. W., Bilderback, D., Fontes, E., Wixted, R., Barna, S. \& Gruner, S. M. (1999). J. Synchrotron Rad. 6, 1096-1105.

Schaeben, H., Hielscher, R., Fundenberger, J.-J., Potts, D. \& Prestin, J. (2007). J. Appl. Cryst. 40, 570-579.

Schlepütz, C. M., Herger, R., Willmott, P. R., Patterson, B. D., Bunk, O., Brönnimann, Ch., Henrich, B., Hülsen, G. \& Eikenberry, E. F. (2005). Acta Cryst. A61, 418-425.

Skrotzki, W., Klöden, B., Tamm, R., Oertel, C.-G., Garbe, U. \& Rybacki, E. (2003). Textures Microstruct. 35, 163-173.

Skrotzki, W., Tóth, L., Klöden, B., Brokmeier, H. \& Arruffat-Massion, R. (2008). Acta Mater. 56, 3439-3449.

Smilgies, D. (2002). Rev. Sci. Instrum. 73, 1706-1710.

Stroustrup, B. (2009). Programming: Principles and Practice Using $C++$. Boston: Addison-Wesley.

Vlieg, E. (1997). J. Appl. Cryst. 30, 532-543.

Vlieg, E. (2000). J. Appl. Cryst. 33, 401-405.

Voltolini, M., Wenk, H.-R., Gomez Barreiro, J. \& Agarwal, S. C. (2011). J. Appl. Cryst. 44, 928-934.

Wenk, H.-R. (1991). J. Appl. Cryst. 24, 920-927.

Wenk, H.-R., Cont, L., Xie, Y., Lutterotti, L., Ratschbacher, L. \& Richardson, J. (2001). J. Appl. Cryst. 34, 442-453.

Wenk, H.-R. \& Grigull, S. (2003). J. Appl. Cryst. 36, 1040-1049.

Wenk, H.-R., Monteiro, P. J. M., Kunz, M., Chen, K., Tamura, N., Lutterotti, L. \& Del Arroz, J. (2009). J. Appl. Cryst. 42, 429-432.

Zou, H. F. \& Zhang, Z. F. (2010). J. Appl. Phys. 108, 103518. 
Journal of

Applied Crystallography

ISSN 1600-5767

\section{addenda and errata}

\section{Fast pole figure acquisition using area detectors at the DiffAbs beamline - Synchrotron SOLEIL. Erratum}

\section{Cristian Mocuta, ${ }^{a *}$ Marie-Ingrid Richard, ${ }^{b, c}$ Julie Fouet, $^{b}$ Stefan Stanescu, ${ }^{a}$ Antoine Barbier, ${ }^{\text {d }}$ Christophe Guichet, ${ }^{b}$ Olivier Thomas, ${ }^{b}$ Stéphanie Hustache, ${ }^{a}$ Alexey V. Zozulya $^{a} \ddagger$ and Dominique Thiaudière ${ }^{a}$}

asynchrotron SOLEIL, L'orme des Merisiers, Saint Aubin - BP 48, Gif-sur-Yvette, 91192, France, bIM2NP UMR 7334, Aix-Marseille Université, CNRS, Campus de St Jérôme, Marseille Cedex 20, 13397, France, ' ID-01 beamline, ESRF, 6 rue Jules Horowitz, Grenoble, 38043, France, and d DSM/IRAMIS/SPCSI, CEA-Saclay, Gif-surYvette, 91191, France. Correspondence e-mail: mocuta@synchrotron-soleil.fr

Errors in the article by Mocuta, Richard, Fouet, Stanescu, Barbier, Guichet, Thomas, Hustache, Zozulya \& Thiaudière [J. Appl. Cryst. (2013), 46, 1842-1853] are corrected.
In the article by Mocuta et al. (2013, $\$ 3$, p. 1845), there is an error in the referencing of programs used to deal with the treatment of X-ray data acquired using area detectors. Rather than 'FIT2D (Boesecke, 2007; http://www.esrf.eu/computing/scientific/FIT2D)', the text should read 'SAXS (Boesecke, 2007), FIT2D (Hammersley et al., 1994, 1996; http://www.esrf.eu/computing/scientific/FIT2D)'.

\section{References}

Boesecke, P. (2007). J. Appl. Cryst. 40, s423-s427.

Hammersley, A. P., Svensson, S. O., Hanfland, M., Fitch, A. N. \& Häusermann, D. (1996). High Pressure Res. 14, 235-248.

Hammersley, A. P., Svensson, S. O. \& Thompson, A. (1994). Nucl. Instrum. Methods Phys. Res. Sect. A, 346, 312-321.

Mocuta, C., Richard, M.-I., Fouet, J., Stanescu, S., Barbier, A., Guichet, C., Thomas, O., Hustache, S., Zozulya, A. V. \& Thiaudière, D. (2013). J Appl. Cryst. 46, 1842-1853.

$\ddagger$ Present address: DESY, Notkestrasse 85, Hamburg, 22607, Germany. 